\title{
ЭФФЕКТИВНОСТЬ ПРОГРАММ ЭКСТРАКОРПОРАЛЬНОГО ОПЛОДОТВОРЕНИЯ С ПРИМЕНЕНИЕМ ПРЕИМПЛАНТАЦИОННОГО ГЕНЕТИЧЕСКОГО ТЕСТИРОВАНИЯ У ЖЕНЩИН С НАРУЖНЫМ ГЕНИТАЛЬНЫМ ЭНДОМЕТРИОЗОМ
}

\author{
Витязева И.И., Красовская Р.Л., Дружинина А.С., Мун Т.В., Саватеева Н.А. \\ ФГБУ «НМИЦ эндокринологии» Минздрава России, отделение ВРТ
}

\begin{abstract}
Наружный генитальный эндометриоз (НГЭ) является одной из самых актуальных проблем акушерства и гинекологии на данный момент. Благодаря своей мультифакториальной природе нарушения фертильности, высокой частоте заболеваемости, НГЭ является важным фактором бесплодия, ведущим к непроходимости маточных труб, снижению овариального резерва и качества ооцитов и, как следствие, нарушению эмбриогенеза.
\end{abstract}

Преимплантационное генетическое тестирование (ПГТ) позволяет выявить эмбрионы с численными и структурными хромосомными аномалиями и повысить результативность программ ЭКО у данной группы пациенток.

ЦЕЛЬ: оценить частоту наступления беременности (ЧНБ) в программе ЭКО у пациенток с эндометриоз-ассоциированным бесплодием, долю эмбрионов с анеуплоидиями.

МАТЕРИАЛЫ И МЕТОДЫ: исследование ретроспективное. Проанализированы данные историй болезни 25 пациенток в возрасте от 21 до 37 лет с нормальным кариотипом супругов, прошедших лечение бесплодия методом ЭКО в 2019 г. в рамках клинической апробации «Повышение эффективности программ экстракорпорального оплодотворения у женщин с наружным генитальным эндометриозом на основании преимплантационного генетического скрининга методом сравнительной геномной гибридизации». Критерии исключения: наличие тяжелой патозооспермии у мужчины (концентрация сперматозоидов менее 3×1000000/мл, наличие не менее 3\% морфологически нормальных сперматозоидов по строгим критериям Крюгера, а также наличие азооспермии), уровень антимюллерова гормона не менее 0,6 нг/мл, фолликулостимулирующего гормона не более 12 мME/мл, не более 1-го неэффективного протокола ЭКО в анамнезе. На ПГТ отправлялись эмбрионы только категории: АА, АВ и ВB (по Гарднеру).

PЕЗУЛЬТАТЫ: по результатам клинической апробации у 3 (12\%) пациенток зафиксирована остановка эмбрионов до 5 суток развития. После проведения биопсии клеток трофэктодермы на 5 сутки эмбриогенеза, на проведение ПГТ был отправлен 61 биоптат. По результатам ПГТ у 20 (80\%) пациенток был получен 41 эуплоидный эмбрион, что составило 67\% от числа проанализированных эмбрионов. У 2 (8\%) пациенток по результатам ПГТ эмбрионы не рекомендованы к проведению переноса в полость матки в виду их анеуплоидности. Было проведено 20 селективных переносов эуплоидных эмбрионов в полость матки. ЧНБ составила 70\% ( $\mathrm{n}$ - 14). Частота неразвивающейся беременности малого срока составила $15 \%$ ( $\mathrm{n}-3)$. Зафиксирован один случай (5\%) наступления эктопической (трубной) беременности.

Выводы: несмотря на прогресс вспомогательных репродуктивных технологий в современном мире, барьер в 30-35\% в наступлении беременностей в свежем переносе не удается преодолеть. Применение жесткого отбора эмбрионов на процедуру преимплантационного генетического тестирования и сама процедура тестирования, даже с учетом ее инвазивности, позволяет увеличить эту цифру вдвое и избежать передачи грубых хромосомных аномалий плоду. 